\title{
How bad is the mere presence of a phone? A replication of Przybylski and Weinstein (2013) and an extension to creativity
}

\author{
Claire Linares $\mathbb{1}^{*}$, Anne-Laure Sellier \\ Department of Marketing, HEC Paris, Jouy-en-Josas, France \\ * claire.linares@ hec.edu
}

\section{Abstract}

A 2013 article reported two experiments suggesting that the mere presence of a cellphone (vs. a notebook) can impair the relationship quality between strangers. The purpose of the present research is twofold: (1) closely replicate this article's findings, and (2) examine whether there may be an impact of the mere presence of a phone on creativity, whether at a group- or an individual- level. In two experiments ( $N=356$ participants, 136 groups), we followed the original procedure in the 2013 article. In particular, groups of participants who had never seen each other before the study had a conversation in the mere presence of either a

\section{G openaccess}

Citation: Linares C, Sellier A-L (2021) How bad is the mere presence of a phone? A replication of Przybylski and Weinstein (2013) and an extension to creativity. PLoS ONE 16(6): e0251451. https:// doi.org/10.1371/journal.pone.0251451

Editor: Jeff Galak, Carnegie Mellon Univeristy, UNITED STATES

Received: February 22, 2021

Accepted: April 23, 2021

Published: June 9, 2021

Copyright: @ 2021 Linares, Sellier. This is an open access article distributed under the terms of the Creative Commons Attribution License, which permits unrestricted use, distribution, and reproduction in any medium, provided the original author and source are credited.

Data Availability Statement: All relevant data are in the Supporting Information files.

Funding: This work was supported by the HEC Foundation. The funder had no role in study design, data collection and analysis, decision to publish, or preparation of the manuscript.

Competing interests: The authors have declared that no competing interests exist.

\section{Introduction}

Through smartphones, people exchange in new ways, whether on social media or remote work applications. Most individuals are now connected to others almost constantly. To illustrate, American adults reportedly spend more than one hour each day networking on their smartphones [1] and more than $40 \%$ of English teenagers check social media after going to bed [2]. Even texting while sleeping_-now referred to as sleep texting_keeps increasing among teenagers and college students [3]. Other than the extensive research documenting the heavy use of smartphones [e.g., 4-11], a few researchers published data suggesting that the mere presence of a mobile device is enough to harm social interactions $[12,13]$.

The possibility that the mere presence of a phone may actively and significantly shape the quality of social interactions is a formidably important question for society, given the ubiquity of mobile devices today $[14,15]$. This research examines this question, and its purpose was 
twofold: first, we sought to replicate the findings that the mere presence of a phone can harm social interactions [12]. Second, we investigated whether similar harming effects of the mere presence of a phone may exist for creative cognition. In particular, we ask if groups and/or individuals engaged in a creative process perform differently, depending on whether a phone (vs. a notebook) is merely present.

\section{The mere presence of phones can harm social interactions: Evidence}

Two articles present data suggesting a harmful effect of the mere presence of a phone on social interactions: Przybylski and Weinstein [12] and Misra, Cheng, Genevie, and Yuan [13]. In two studies collected in 2012 at the latest, Przybylski and Weinstein [12] shared concerning evidence that the mere presence of a mobile phone impairs relationship formation. In both studies, they found that dyads of strangers who were unobtrusively exposed to a cellphone felt a significantly lower sense of connection to their conversation partners, trusted them significantly less, and perceived less empathy from them than those exposed to a notebook.

In another study conducted in a coffee shop, Misra et al. [13] invited dyads of customers to have a conversation and noted whether the participants had a mobile device taken out during the conversation. In this study, the mobile device could be the participants' own phones, tablets, or laptops. The findings were consistent with Przybylski and Weinstein [12]. Groups in presence of a mobile device reported a significantly lower connectedness to their partners and perceived empathy from them.

In the current research, we chose to focus on the relatively more controlled lab experiments in Przybylski and Weinstein [12]. In particular, they controlled for the type of mobile device (i.e., a phone) and included participants who did not know each other before the study. Given the formidable implications of their results [12], their reported effect of the mere presence of a mobile phone has been widely cited in academic research [e.g., 16-19] as well as in mainstream publications [e.g., 20-23]. Eight years after their article, however, it remains to be seen whether the adverse impact of the mere presence of a mobile phone on social interactions can be replicated, for at least two reasons. A first reason is that the evidence available remains limited, particularly in light of how widely cited this research is. We do note the interesting work by Courtright and Caplan [24], who concluded from a meta-analysis of only six studies that the mere presence of mobile phone effect is overall unsupported [12, 13, 25-27]. However, to the best of our knowledge, there is no direct evidence either confirming or invalidating the impact of the mere presence of a mobile phone on relationship formation, as Przybylski and Weinstein [12] documented it. Indeed, all replication attempts were only partial and substantially deviated from the original procedure. They involved either confederates, who had repeated conversations with participants, or pairs of participants who knew each other prior to the study [13, 25-27]. In addition, except in Misra et al.'s [13] field study, one of the conversation partners (either the confederate or one of the participants) was aware of the phone's presence because of the procedure itself [25-27]. As a result, an attempt to replicate Przybylski and Weinstein's [12] exact results would be valuable. A second reason for which a full replication of Przybylski and Weinstein [12] is helpful is that individuals may simply have gotten used to having smartphones to the point that there may be no mere phone presence effect any longer.

In this research, we provide an independent replication of Przybylski and Weinstein's Study 1 [12]. This endeavor answers a call for direct replications before exploring an effect's generalization [e.g., 28-30]. Such replications are particularly valuable for surprising phenomena exposed to an inflated risk of false-positive due to the publication of only successful experiments [31, 32]. In the case of Przybylski and Weinstein [12], another reason why a replication would be important is that their sample sizes were low $(N=37$ groups for two conditions in 
Study 1; $N=34$ groups for four conditions in Study 2) [29,33]. Finally, as Przybylski and Weinstein's [12] results were reported with covariates (gender, age, and positive affect), a nonrobust effect is possible $[29,34]$.

\section{The mere presence of phones and creativity}

The second aim of this research was to assess a possible impact of the mere and pervasive presence of a smartphone on our highest cognitive function: creativity [35]. Any creative effect of the mere presence of a phone-whether beneficial or detrimental-would be critical to document, considering the crucial role of creativity in society, to solve everyday problems [36, 37], as well as fuel artistic inspiration and innovation [38-41].

If there is a deleterious effect of the mere presence of a phone on the quality of social interactions [12], it is reasonable to consider that group creativity, in turn, may be compromised [e.g., 38, 42, 43]. Considerable past research gives hints of a possible negative effect of the mere presence of a phone on creativity. For example, extensive management research has highlighted the need for a supportive climate to enable team members to overcome their fear of judgment and voice their creative ideas [e.g., 42, 44-46]. Przybylski and Weinstein's [12] findings would suggest that the mere presence of a phone may hurt group creativity, since it would presumably prevent an optimal relationship between group members. Another example is research showing that the mere presence of a mobile phone taxes working memory [47-51], which is another critical antecedent of creative thinking. Working memory is needed to transform preliminary mental idea components into creative ideas [52-55], and one type of working memory-short-term memory-is an additional aid in group-settings to remember others' ideas and stimulate one's idea generation, as well as to avoid idea loss when waiting to speak $[56,57]$.

Note that some research suggests that there may be a positive effect of the mere presence of a phone on creativity. The mere exposure to a mobile phone was shown to divert attention away from a focal task [47, 49-51]. In turn, research suggests that diverting the attention away from a creative task can be beneficial to generate ideas and solutions [40, 58-60]. Therefore, we tackled our exploratory investigation on group creativity with a two-tailed prediction, whereby the mere presence of a smartphone may enhance or impair group creative performance. We added a subsidiary exploration pertaining to individual-level creativity, as it could be affected by the mere presence of a smartphone through similar cognitive processes.

\section{Overview}

Our studies followed a two-step approach. We first followed a procedure as close as possible to Przybylski and Weinstein's [12] Study 1 in order to replicate their findings. We then extended this procedure and added a group creativity task and an individual creativity task (Fig 1), in order to examine whether Przybylski and Weinstein's [12] manipulation may rub off on creative cognition or the experience of the creative process.

In the first part, groups of participants were assigned to one of two conditions, the mere presence of either a smartphone or a notebook. Note that in our studies, we used a standard smartphone rather than a cellphone as in Przybylski and Weinstein [12], since it is today's mainstream mobile device. Each group was instructed to have a conversation about an interesting event that occurred to them over the last month [12]. In the second part, participants were given a group creativity assignment where they had to create a toy for a child [37, 61], which was subsequently assessed by peer raters on originality and appropriateness [35, 37, 62]. As a last exploration on individual creativity (Study 1), participants did a remote associates test (RAT [63]). Following these tasks, participants answered a questionnaire with the social 


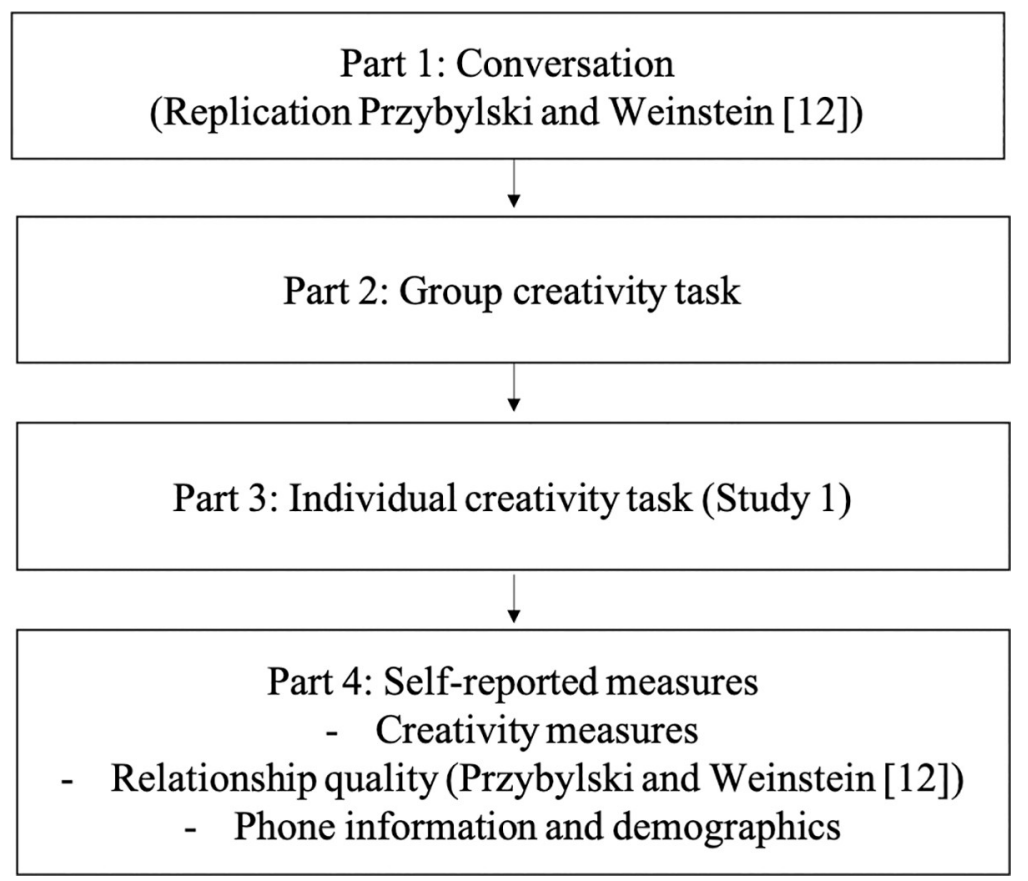

Fig 1. Procedure followed in Studies 1 and 2. The procedure was composed of several parts.

https://doi.org/10.1371/journal.pone.0251451.g001

measures from Przybylski and Weinstein [12], as well as creativity measures. In Study 1, participants were split primarily in dyads, and occasionally in triads when one participant was absent. Because we found promising results on triads, we pursued our investigation in Study 2 with triads only.

\section{Methods}

The studies were approved by the Institutional Review Board of the Centre de Recherche Multidisciplinaire Sorbonne Universités-INSEAD. All participants provided written consent. All the stimuli, additional pictures, $\mathrm{R}$ code, and datasets are accessible in the Supporting information. The data were collected in 2018, at a time where preregistration was not required for exploratory studies. For this reason, the two studies were not preregistered. We have deposited our laboratory protocols in protocols.io to ensure reproducibility of our results.

\section{Study 1}

Participants. One hundred and forty-eight participants ( $62 \mathrm{men}, 86$ women, $M_{\text {age }}=22.82$ years, $S D=3.24$ ) from a European research lab were invited to complete a study about "Group Interactions" in return for 12 euros. Upon arriving at the lab, participants were randomly assigned to one of two conditions between-subjects (mere presence of a smartphone vs. mere presence of a notebook). Participants registered in sessions of four, initially to form two dyads per session. However, we had to compose triads when one participant in the session was absent. In total, 67 groups (53 dyads and 14 triads) completed the study successfully. One dyad was excluded from the analysis because one member had been speaking the local language for only four years, which could have prevented them from understanding all the instructions and prevented their group from fully understanding each other. In turn, we reasoned that it may have affected the relationship quality, and/or group and individual creativity. We kept 
participants who were not native speakers but had been speaking the local language for 15 years or more, allowing a good understanding of the instructions and the other group members. Note that including all participants in our analysis does not affect the results reported here. We report the results for the remaining 66 valid groups (52 dyads, 14 triads, 146 participants).

Procedure. Part 1: Replication of Przybylski and Weinstein [12]. At the beginning of the session, participants were asked whether they had ever talked to another member of the session before, including while waiting for the study to start. Based on their responses, we formed either one or two groups of participants, each of which was settled in a study room to start the study. Before entering the study room, participants left their personal belongings, including their phones, in a locker room, similarly to Przybylski and Weinstein [12]. Each group was assigned to its own room where there were two tables, the first one with the smartphone or notebook and the second one to be used for the creativity tasks. When the participants entered the room, chairs were placed next to the first table. For dyads, the layout of the room was strictly identical to the schema displayed in Przybylski and Weinstein [12] (Fig 2A), such that the smartphone or notebook was next to the participants but outside of their direct visual field. For triads, the layout was slightly adapted, such that one participant in the group faced the table while the two others were seated like the dyads (Fig 2C). The second table stayed in the corner of the room during the whole conversation task.

Przybylski and Weinstein [12] did not provide any information about the phone and notebook they used. We chose a nondescript black smartphone with a minimal design (S1 Picture)

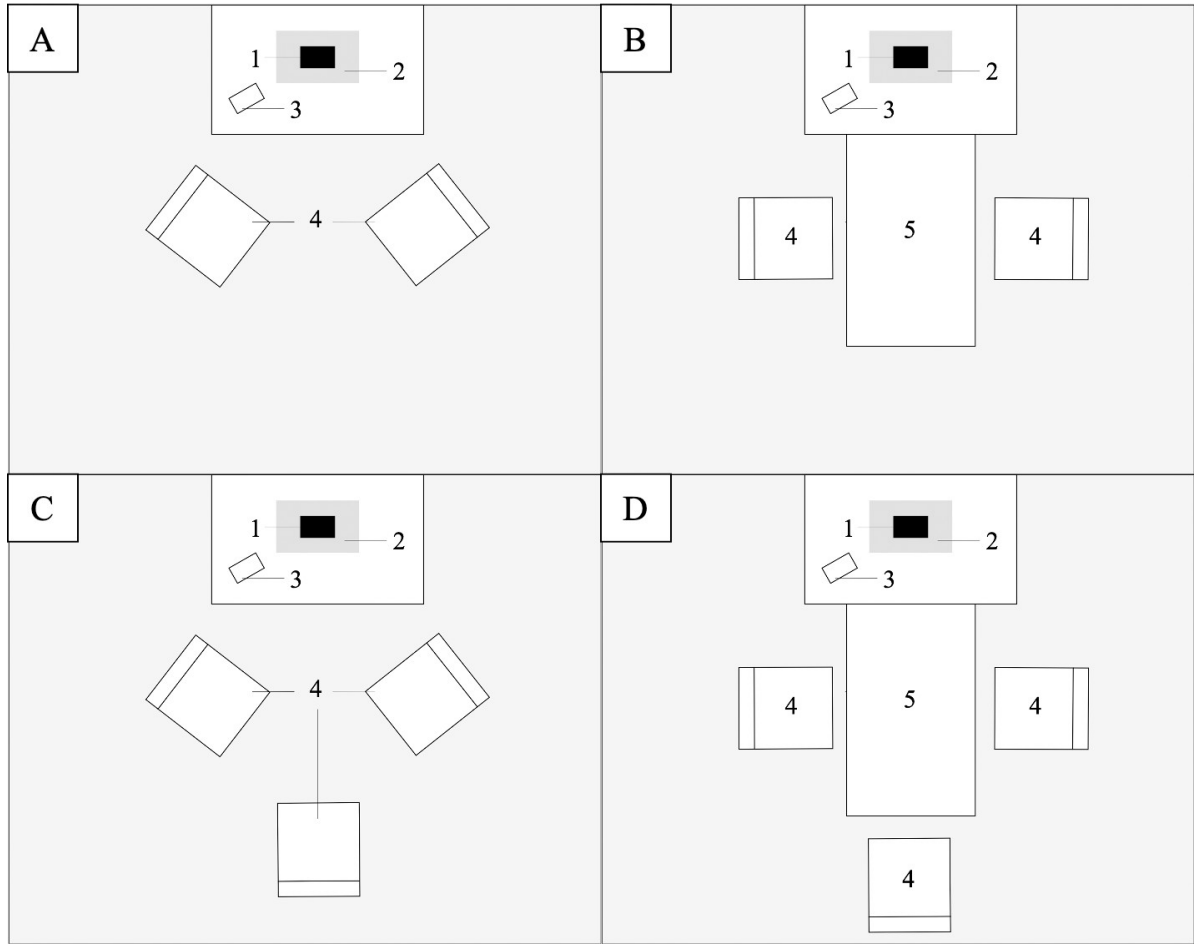

Fig 2. Layout of the study rooms during the conversation and creativity tasks (Studies 1 and 2). Schematic drawings of a bird's eye view of the study rooms during the conversation for dyads (A) and triads (C), and during the creative tasks for dyads (B) and triads (D). In the rooms, the smartphone or notebook (1) was placed on a paper sleeve (2), next to a clock (3) on the main table. Chairs (4) were placed next to the main table. A second table (5) was added for the creative tasks. Adapted from Przybylski and Weinstein [12].

https://doi.org/10.1371/journal.pone.0251451.g002 
and a brand that was not well-known and not visible at first sight to avoid any brand effects, on creativity in particular [64]. In the absence of information, we positioned the smartphone's screen facing up as has been done in other research on the mere presence of a smartphone [50]. In the control condition, the pocket notebook was chosen to be approximatively the same size and color (i.e., black) as the smartphone (S1 Picture). Underneath the object, we placed a purple paper sleeve instead of a book in Przybylski and Weinstein [12]. In both conditions, we chose to place a clock next to the smartphone or notebook to minimize the temptation for participants to look at the phone to monitor time (S1 Picture).

We emphasize that, as in the original article, we did not mention the smartphone or the notebook to participants during the tasks to focus our investigation on the effect of the smartphone's mere presence. At the very end of the tasks and before moving to the final questionnaire, two participants asked whether someone had forgotten their phone and one participant in the notebook condition asked where it came from, that is whether it had been placed on the table during the tasks. As exploratory measures, we probed participants about the presence of the phone in the final questionnaire to see how many were aware of its presence and what were their thoughts, and again orally at the very end of the session both for the phone and the notebook. We report the results of these exploratory data for both Studies 1 and 2 in the appendix (S1 Appendix). Critically, note that the results we report below remain unchanged whether we remove (1) participants in the phone condition who were not aware of the presence of the phone, (2) groups where none of the participants was aware of the phone's presence, and (3) groups where at least some members did not see the phone.

Once they were settled, participants were asked for their first names and were given the same relationship formation task as in Przybylski and Weinstein's Study 1 [12]. In particular, they had to "discuss an interesting event that occurred to them over the past month" during 10 minutes [65].

Part 2: Group creativity task. When the time was up, we came back into the study room and added the second table next to the first one such that the smartphone or notebook remained in the same visual field as before (Fig 2B and 2D). We then gave participants the instructions for a widely used divergent creativity task, the "toy task" [e.g., 37, 61]. Each group was asked to design a new toy, as creative as possible, for a child from 5 to 11 to play with, using shapes from a given list (S2 Appendix). Participants had 15 minutes to draw the group's toy on a piece of paper and were reminded of the time when there were only 5 minutes left. They also had to list five reasons why their toy was creative. Once the time was over, they wrote a small description about the toy and the way it worked.

Part 3: Individual creativity task. Next, participants were given an individual convergent creativity task, the remote associates test (RAT, [63, 66]; S3 Appendix). They had up to 10 minutes to solve 10 RATs while they were still in the study room in presence of the smartphone or notebook. They were instructed not to talk to each other.

Part 4: Self-reported measures. The final part of the study took place in individual cubicles where each participant completed three series of measures (S4 Appendix). First, participants indicated how creative they thought their group toy was on six items pertaining to originality and appropriateness (1-7 = "not at all" / "extremely creative / original / novel / useful / appropriate / practical"). A factor analysis of these items revealed that they loaded on two factors, originality and appropriateness, as in the bulk of prior creativity research [35]. For this reason, we averaged self-assessments of creativity, originality and novelty $(\alpha=0.81)$ to create an originality score. We also averaged the usefulness, appropriateness and practicality items to create an appropriateness index $(\alpha=0.67)$. Participants also indicated how satisfied they felt about the toy through three seven-point items that were averaged to form a satisfaction score ( $\alpha=$ $0.87)$. Then, they completed creative process measures, all on seven-point scales. These 
measures captured the pleasantness $(\alpha=0.86)$ and easiness of the process $(r=0.63, p<0.001)$, the appreciation of group work $(\alpha=0.83)$, group cohesion $(\alpha=0.90)$, risk-taking $(r=0.73$, $p<0.001)$, intrinsic motivation $(r=0.51, p<0.001)$, feelings of competence, autonomy and control.

The second series of measures pertained to the initial conversation and were taken from Przybylski and Weinstein [12]. It included an assessment of relationship quality from the relatedness subscale of the Intrinsic Motivation Inventory [67]. As Przybylski and Weinstein [12], we used seven of the eight original items $(\alpha=0.84)$. We will also report the results for the two items on trust separately as they are close to the trust measures reported in the original article $(r=0.46, p<0.001 ;[12])$. We added three new items on relationship quality (e.g., "I had the impression I could create a relationship with the other participant(s)," $\alpha=0.73)$. Following Przybylski and Weinstein [12], we measured partner closeness with the Inclusion of Other in the Self Scale [65], partner empathy ("To what extent do you think your partner(s) accurately understood your thoughts and feelings about the topic"; Empathic Concern Scale, [68]) with an additional item on participants' own empathy toward their partner(s). In addition, we measured interest in the discussion and self-reports of distraction. We included the PANAS scale to control for positive affect ( $\alpha=0.77$, [69]) slightly deviating from Przybylski and Weinstein [12] who used the Emmons Mood Indicator [70]. The last part of the questionnaire included questions on phone ownership and usage, and ended with demographics questions (e.g., gender, age, language) and mood measures. Participants were probed for suspicions, both in the written questionnaire and orally. None of the participants guessed the purpose of the study. Finally, participants were debriefed and thanked.

Statistical analysis. As participants were nested into groups, our data structure is hierarchical, with the manipulation (smartphone vs. notebook) at level-2 and the dependent variables either at level-1 (e.g., relationship quality, RAT scores, self-reported measures) or at level-2 (group toy creativity scores), requiring different analytical strategies (Table 1).

For level-1 dependent variables, the standard analysis for hierarchical data is multilevel linear modelling, which Przybylski and Weinstein [12] used. We conducted identical analyses for our replication measures. The model is specified as follows:

$$
\mathrm{Y}_{i j}=\left(b_{0}+u_{0 j}\right)+b_{1} \mathrm{X}_{i j}+b_{2} \text { Gender }_{i j}+b_{3} \text { Age }_{i j}+b_{4} \text { Positive affect }_{i j}+\varepsilon_{i j}
$$

where $Y_{i j}$ is the dependent variable (e.g., relationship quality) of an individual $i$ of group $j ; b_{0}$ and $u_{0 j}$ are the fixed and random intercept coefficients; $b_{1}$ is the parameter associated to the fixed effect of the independent variable $\mathrm{X}_{i j}$ (smartphone vs. notebook); $b_{2}, b_{3}$, and $b_{4}$ are the parameters associated to the covariates (gender, age, and positive affect). The model is thus a

Table 1. Summary of main analyses for the different categories of dependent variables (Studies 1 and 2).

\begin{tabular}{l|l}
\hline Category of dependent variables & Main analysis \\
\hline $\begin{array}{l}\text { Relationship measures (Przybylski and } \\
\text { Weinstein [12]) }\end{array}$ & $\begin{array}{l}\text { Multilevel analysis: random intercept model with mere presence of } \\
\text { smartphone as level-2 fixed effect, and gender, age, and positive affect } \\
\text { covariates as level-1 fixed effects }\end{array}$ \\
\hline $\begin{array}{l}\text { Creativity scores of group toys rated } \\
\text { by peer judges }\end{array}$ & $t$ test: mere presence of smartphone as predictor (no covariates) \\
\hline Remote associates test (Study 1) & $\begin{array}{l}\text { Multilevel analysis: random intercept model with mere presence of } \\
\text { smartphone as level-2 fixed effect (no covariates) }\end{array}$ \\
\hline Self-assessments of creativity & $\begin{array}{l}\text { Multilevel analysis: random intercept model with mere presence of } \\
\text { smartphone as level-2 fixed effect (no covariates) }\end{array}$ \\
\hline Creative measures & $\begin{array}{l}\text { Multilevel analysis: random intercept model with mere presence of } \\
\text { smartphone as level-2 fixed effect (no covariates) }\end{array}$ \\
\hline
\end{tabular}

https://doi.org/10.1371/journal.pone.0251451.t001 
random intercept one where only the intercept can vary across groups. We used a maximum likelihood estimation method which provides more accurate estimates of the fixed effect parameters [71] as we were primarily interested in the fixed effect of the smartphone versus notebook. The age and positive affect covariates were grand-mean centered. The positive affect variable was the average of the 10 positive affect items from the PANAS scale [69]. The conclusions are the same when removing all covariates from the model. It should be noted that some of the intraclass correlations were low (below 0.001), which indicates a limited impact of clustering on the data [72]. For the level-1 dependent variables other than relationship quality measures (i.e., RAT scores, other self-reported measures), we also used a random intercept multilevel model but we did not include the covariates in our main analyses. For level-2 toy creativity scores, we conducted $t$ tests as both the manipulation and the dependent variables were at the group-level.

In Study 1, we first conducted analyses on dyads to closely follow Przybylski and Weinstein [12]. We then extended the analyses to triads, and finally to dyads and triads taken together. Study 2 included only triads. The level of significance was set at a two-tailed $p$ value of 0.05 . Multilevel analyses were performed in R using the nlme package for the model estimations and the performance package for the ICCs. Results remain the same with SPSS and the R package Ime4. $T$ tests were performed in SPSS.

Results. Relationship quality (Przybylski and Weinstein [12]). Tables 2 and 3 present the results of our multilevel analyses for dyads compared with results reported in Przybylski and Weinstein [12]. In contrast to Przybylski and Weinstein [12], we did not find a significant effect of the mere presence of a mobile phone (vs. notebook) on any of the original relationship measures, all $p s>0.45$. We also did not find any effect on new measures of relationship quality, all $p s>0.18$. As expected, positive affect was significantly and positively related to most of the relationship measures (all $b s>0, p s<0.01$ ) except to the trust items $(p=0.88)$, while age and gender were not related to any measures (all $p s>0.14$ ). Subsequent analyses on triads

Table 2. Descriptive statistics of relationship measures for dyads (Study 1). Means and standard deviations by condition, sample sizes. Comparison with information reported in Przybylski and Weinstein [12].

\begin{tabular}{|c|c|c|c|}
\hline & & Phone & Notebook \\
\hline & $N_{\text {groups }}$ & $M(S D)$ & $M(S D)$ \\
\hline \multicolumn{4}{|l|}{ Przybylski and Weinstein [12]. Study 1} \\
\hline Relationship quality & 37 & \multicolumn{2}{|c|}{$2.78(0.79)$} \\
\hline Partner closeness & 37 & \multicolumn{2}{|c|}{$3.57(1.46)$} \\
\hline \multicolumn{4}{|l|}{ Przybylski and Weinstein [12]. Study 2} \\
\hline Relationship quality & 34 & \multicolumn{2}{|c|}{$4.98(1.09)$} \\
\hline Trust & 34 & \multicolumn{2}{|c|}{$3.25(1.01)$} \\
\hline Partner empathy & 34 & \multicolumn{2}{|c|}{$4.98(1.09)$} \\
\hline \multicolumn{4}{|l|}{ Study 1 (this paper)-Dyads only } \\
\hline Relationship quality & 52 & $5.26(1.02)$ & $5.09(1.02)$ \\
\hline Trust (subscale) & 52 & $5.74(0.98)$ & $5.76(1.10)$ \\
\hline Additional items relationship quality & 52 & $5.28(1.18)$ & $5.08(1.30)$ \\
\hline Partner closeness & 52 & $3.92(1.61)$ & $3.83(1.56)$ \\
\hline Partner empathy & 52 & $3.85(0.83)$ & $3.94(0.85)$ \\
\hline Own empathy & 52 & $3.88(0.83)$ & $3.65(1.03)$ \\
\hline Experience appreciation & 52 & $5.71(1.23)$ & $5.78(1.05)$ \\
\hline Concentration & 52 & $5.99(1.07)$ & $6.02(1.01)$ \\
\hline
\end{tabular}

Descriptive statistics for triads, and dyads and triads together are reported in the S1 Table.

https://doi.org/10.1371/journal.pone.0251451.t002 
Table 3. Multilevel analyses for relationship measures of dyads (Study 1). Intraclass correlations, fixed effects estimates, and significance tests for the manipulation and covariates. Comparison with results reported in Przybylski and Weinstein [12].

\begin{tabular}{|c|c|c|c|c|c|c|c|c|c|c|c|c|c|}
\hline & \multirow[b]{2}{*}{ ICC } & \multicolumn{3}{|c|}{$\begin{array}{c}\text { Fixed effect level-2 } \\
\text { phone }\end{array}$} & \multicolumn{3}{|c|}{$\begin{array}{c}\text { Fixed effect level-1 covariate } \\
\text { gender }\end{array}$} & \multicolumn{3}{|c|}{$\begin{array}{l}\text { Fixed effect level-1 covariate } \\
\text { age }^{\mathrm{a}}\end{array}$} & \multicolumn{3}{|c|}{$\begin{array}{c}\text { Fixed effect level-1 covariate } \\
\text { positive affect }^{\mathbf{a}}\end{array}$} \\
\hline & & $\boldsymbol{b}$ & $t$ & $p$ & $\boldsymbol{b}$ & $t$ & $p$ & $\boldsymbol{b}$ & $t$ & $p$ & $\boldsymbol{b}$ & $t$ & $p$ \\
\hline \multicolumn{14}{|c|}{ Przybylski and Weinstein [12]. Study 1} \\
\hline Relationship quality & $\begin{array}{c}0.43- \\
0.51\end{array}$ & -0.99 & 3.08 & 0.004 & -20 & -0.61 & 0.55 & -0.04 & -0.03 & 0.12 & 0.80 & 2.99 & $\begin{array}{c}< \\
0.001\end{array}$ \\
\hline Partner closeness & $\begin{array}{c}0.43- \\
0.51\end{array}$ & -0.39 & -2.56 & 0.02 & $\begin{array}{l}-0.00- \\
-0.09\end{array}$ & $\begin{array}{c}-0.06- \\
-0.64\end{array}$ & $\stackrel{>}{0.51}$ & $\begin{array}{l}-0.00- \\
-0.09\end{array}$ & $\begin{array}{l}-0.06- \\
-0.64\end{array}$ & $\overrightarrow{>}$ & $\begin{array}{l}-0.00- \\
-0.09\end{array}$ & $\begin{array}{l}-0.06- \\
-0.64\end{array}$ & $>0.51$ \\
\hline \multicolumn{14}{|c|}{ Przybylski and Weinstein [12]. Study 2} \\
\hline Relationship quality & $\begin{array}{c}0.39- \\
0.47\end{array}$ & -0.19 & -2.29 & 0.03 & $\begin{array}{c}0.01- \\
0.09\end{array}$ & $0.13-1.28$ & $\stackrel{>}{0.20}$ & $\begin{array}{c}0.01- \\
0.09\end{array}$ & $0.13-1.28$ & $\stackrel{>}{0.20}$ & $\begin{array}{c}0.01- \\
0.09\end{array}$ & $0.13-1.28$ & $>0.20$ \\
\hline Trust & $\begin{array}{c}0.39- \\
0.47\end{array}$ & -0.36 & -3.76 & $\begin{array}{c}< \\
0.001\end{array}$ & $\begin{array}{c}0.02- \\
0.13\end{array}$ & $-0.13-1.50$ & $\stackrel{>}{0.12}$ & $\begin{array}{c}0.02- \\
0.13\end{array}$ & $-0.13-1.50$ & $\stackrel{>}{0.12}$ & $\begin{array}{c}0.02- \\
0.13\end{array}$ & $-0.13-1.50$ & $>0.12$ \\
\hline Partner empathy & $\begin{array}{c}0.39- \\
0.47\end{array}$ & -0.37 & -3.60 & 0.002 & -0.08 & -0.29 & 0.77 & 0.04 & 1.92 & 0.06 & 0.21 & 1.55 & 0.13 \\
\hline \multicolumn{14}{|l|}{ Study 1 (this paper)-Dyads only } \\
\hline Relationship quality & 0.10 & 0.16 & 0.75 & 0.456 & -0.20 & -1.01 & 0.318 & 0.02 & 0.59 & 0.557 & 0.50 & 2.85 & 0.006 \\
\hline Trust (subscale) & $<0.001$ & -0.03 & -0.15 & 0.883 & -0.10 & -0.49 & 0.627 & 0.04 & 1.30 & 0.199 & -0.03 & -0.15 & 0.881 \\
\hline $\begin{array}{l}\text { Additional items relationship } \\
\text { quality }\end{array}$ & $<0.001$ & 0.19 & 0.83 & 0.413 & -0.12 & -0.50 & 0.623 & 0.01 & 0.32 & 0.752 & 0.79 & 3.74 & $\begin{array}{c}< \\
0.001 \\
\end{array}$ \\
\hline Partner closeness & $<0.001$ & 0.08 & 0.29 & 0.772 & -0.44 & -1.44 & 0.156 & -0.05 & -1.14 & 0.259 & 0.99 & 3.73 & $\begin{array}{c}< \\
0.001\end{array}$ \\
\hline Partner empathy & $<0.001$ & -0.11 & -0.69 & 0.495 & -0.23 & -1.44 & 0.157 & -0.01 & -0.32 & 0.748 & 0.52 & 3.71 & 0.001 \\
\hline Own empathy & $<0.001$ & 0.23 & 1.33 & 0.190 & 0.01 & 0.04 & 0.971 & -0.01 & -0.49 & 0.627 & 0.60 & 3.80 & $\begin{array}{c}< \\
0.001\end{array}$ \\
\hline Experience appreciation & $<0.001$ & -0.07 & -0.37 & 0.714 & -0.07 & -0.34 & 0.733 & -0.00 & -0.08 & 0.933 & 0.96 & 5.29 & $\begin{array}{c}< \\
0.001\end{array}$ \\
\hline Concentration & $<0.001$ & -0.05 & -0.25 & 0.805 & -0.29 & -1.48 & 0.146 & 0.03 & 0.98 & 0.332 & 0.55 & 3.13 & 0.003 \\
\hline
\end{tabular}

Results for triads, and dyads and triads together, as well as detailed confidence intervals are reported in the S1 Table.

${ }^{a}$ Age and positive affect are grand-mean centered.

https://doi.org/10.1371/journal.pone.0251451.t003

only, and on dyads and triads taken together, revealed no effect of the mere presence of a smartphone on relationship measures (S1 Table).

Group creativity. To assess the creativity of the toys created by groups of participants, 13 peer judges were invited to the lab to independently rate each toy on a series of measures in exchange for $25 €$. The judges were invited in sessions of one or two and brought to a room where all the toy drawings, descriptions and reasons why they were creative, were displayed on the walls. All judges were blind to the hypotheses and conditions, and the toys were presented in one of three random orders. After reading the instructions of the toy task and taking an overview of all the toys, they were first asked to rate each one on its overall creativity. Then, in line with previous research, they had to indicate their ratings on sub-dimensions of creativity, pertaining to originality (i.e., originality, novelty) and appropriateness (i.e., usefulness, practicality, appropriateness) $[39,41]$. All the criteria were evaluated on ten-point scales (e.g., $1=$ "not at all creative" to $10=$ "extremely creative"). Finally, the judges had to indicate how many euros they thought parents would be willing to pay for each toy and completed a final questionnaire including demographics.

We first averaged the 13 valid judges' ratings on each item to obtain mean judges' creativity ( $\alpha=0.85)$, originality $(\alpha=0.84)$, and novelty $(\alpha=0.85)$ scores for each toy. These three scores 
loaded on one factor with high reliability $(\alpha=0.96)$ and were thus averaged to create an overall originality index. Similarly, we computed mean judges' usefulness $(\alpha=0.61)$ and appropriateness scores $(\alpha=0.65)$, and then averaged them to obtain an overall appropriateness index $(r=0.69, p<0.001)$. We analyzed the results of each judge's practicality ratings separately because the interrater reliability for this item was low $(\alpha=0.37)$. We created an index for the estimated parents' willingness to pay by averaging all judges' amounts $(\alpha=0.88)$, which we then logtransformed as it was not normally distributed (Kolmogorov-Smirnov test, $D(66)=$ $0.20, p<0.001)$.

Overall, we found good levels of average originality $(M=4.75, S D=1.34$, dyads and triads) and appropriateness $(M=5.79, S D=0.83)$. We conducted a series of $t$ tests on dyads which did not reveal any effect of the mere presence of a smartphone versus a notebook on the overall originality, appropriateness, and logtransformed willingness to pay indices, all $p s>0.41$, or on any of the judges' practicality ratings (for one judge, $t(50)=1.46, p=0.15$; for the other judges, all $p s>0.27$; S2 Table). However, on triads, $t$ tests revealed a significant effect of the smartphone's mere presence versus the notebook's on the appropriateness of the toys, $t(12)=-3.03$, $p=0.01,95 \%$ CI $[-1.57,-0.26], d=1.69$ (S2 Table), such that the toys created in presence of the smartphone were judged as more appropriate $\left(M_{\text {smartphone }}=6.53, S D_{\text {smartphone }}=0.61\right)$ than those created in presence of the notebook $\left(M_{\text {notebook }}=5.62, S D_{\text {notebook }}=0.36\right)$.

For triads, there was also a significant effect on the willingness to pay, $t(12)=-2.79$, $p=0.02,95 \%$ CI $[-0.51,-0.06], d=1.55$, such that judges estimated a higher parents' willingness to pay for toys created in the mere presence of a smartphone $\left(M_{\text {smartphone }}=1.43\right.$, $S D_{\text {smartphone }}=0.22$, logtranformed values $)$ than of a notebook $\left(M_{\text {notebook }}=1.14, S D_{\text {notebook }}=\right.$ $0.09)$. The toys created in the presence of the smartphone were also judged as marginally more original $\left(M_{\text {smartphone }}=5.84, S D_{\text {smartphone }}=1.38 ; M_{\text {notebook }}=4.57, S D_{\text {notebook }}=0.94 ; t(12)=\right.$ $-1.82, p=0.09,95 \% \mathrm{CI}[-2.79,0.25], d=1.02)$. When analyzing dyads and triads together, there were only marginal effects of the mere presence of the smartphone on the toy creativity item, $p=0.05$, and estimated parents' willingness to pay, $p=0.07$, in the same direction as triads, and no significant effect on any of the other creativity scores.

Individual creativity. The performance at the remote associates test (RAT) was computed with two different methods. The first one used a predetermined list of correct answers (e.g., "Monarchy" associated with the given words "King", "England" and "Crown"). The second one allowed for some flexibility in the answers (e.g., "Queen" was accepted in the previous example). However, according to multilevel analyses, no effect for participants in dyads was observed on either RAT score $\left(M_{\text {correct }}=2.73, S D=1.35 ; M_{\text {flexible }}=4.24, S D=1.21\right.$, dyads and triads), both $p s>0.70$ ( 33 Table). There was also no difference in the number of RAT answers provided, $t(50)=0.76, p=0.45(M=8.32, S D=1.69$, dyads and triads). Results are the same for triads, and dyads and triads combined (S3 Table).

Self-assessments of toy creativity. Multilevel analyses did not reveal any significant effect of the mere presence of a smartphone on dyads' self-assessed toy originality, $t(50)=-0.07$, $p=0.95$; self-assessed toy appropriateness, $t(50)=-1.12, p=0.27$; or satisfaction with the toys, $t(50)=-0.12, p=0.91$. Conclusions remain the same for triads, and dyads and triads combined (S3 Table), except for a marginal effect of the smartphone on triads' satisfaction with their toys such that triads in the phone condition were less satisfied than those in the notebook condition, $t(12)=-1.79, p=0.10$.

Creativity process measures. We ran multilevel analyses on all the toy creative process measures (S3 Table). We found no difference between the smartphone and notebook conditions on ease or enjoyment of the creative process, group cohesion, and group work during the toy creativity task, all $p s>0.34$. Furthermore, we did not find any effects on risk-taking, motivation, feelings of competence, power, control (all $p s>0.21$ ), except a marginal effect on 
autonomy $(t(50)=1.89, p=0.07)$, such that participants in presence of the smartphone felt more autonomous. Results remain the same for triads alone, and dyads and triads together, with the exception of a significant effect of the smartphone's presence on feeling of autonomy, $b=0.42, t(64)=2.04, p=0.05,95 \%$ CI $[0.01,0.82]$, such that groups in presence of the smartphone (vs. the notebook) felt more autonomous when they were creating the toy.

Discussion. In Study 1, we failed to replicate Przybylski and Weinstein's [12] finding that the mere presence of a smartphone impairs relationship quality during a conversation between strangers. We also did not find any effect of the device's presence on creativity, except for triads. Specifically, toys created by triads in the mere presence of a smartphone (vs. a notebook) were judged as more appropriate, and marginally more original. Judges also thought parents would be willing to pay more for them. These findings are consistent with research suggesting that groups can be more or less creative depending on the number of members [e.g., 73-75]. In Study 2, we sought to confirm these results by conducting a study with triads only.

\section{Study 2}

Study 2 aimed to replicate the preliminary findings of Study 1 and confirm the effects of the mere presence of a smartphone on creativity with a greater number of triads. In this study, we also attempted to replicate Przybylski and Weinstein's [12] finding a second time. Overall, the procedure of this study was similar to that of Study 1.

Participants. Two hundred and thirteen participants ( $76 \mathrm{men}, 137$ women, $M_{\text {age }}=21.89$ years, $S D=3.08$ ) from a European research lab took part in the study in return for 10 euros. They were split in 71 triads randomly assigned to one of two conditions between-subjects (mere presence of a smartphone vs. of a notebook). We excluded one triad in which one member had been speaking the local language for only five years. All other participants included in the analysis had been speaking the local language for 10 years or more. The results hold when including all participants who took the study. This left 70 valid triads (210 participants).

Procedure. This study followed the same procedure as Study 1, with the following exceptions. After going through the discussion and toy tasks, participants directly completed the final questionnaire without taking the individual RAT task. During the tasks, two participants in the phone condition and one participant in the notebook condition asked whether they were recorded, without mentioning the smartphone or notebook. No participants made spontaneous comments about the presence of the objects. The final questionnaire included a slightly different set of measures (S5 Appendix). In this study, the self-assessment of toy creativity was measured on creativity, novelty, originality, innovativeness, usefulness, and appropriateness on seven-point scales (e.g., $1=$ "not at all creative" to 7 = "extremely creative"). Selfassessments of toy creativity, novelty, originality and innovativeness loaded on one factor ( $\alpha=$ 0.84 ) and were thus averaged to form a self-assessed originality index, and usefulness and appropriateness were averaged to form a self-assessed appropriateness index $(r=0.40$, $p<0.001)$. In addition, we measured ease $(r=0.50, p<0.001)$ and enjoyment of the creative process $(\alpha=0.85)$, group cohesion ( $\alpha=0.91)$, risk-taking $(r=0.61, p<0.001)$, motivation $(r=0.54, p<0.001)$, and feelings of competence and autonomy. We also included items about feelings of busyness, mind wandering [58] and approach/avoidance [41, 76]. As relationship measures, we only kept the Intrinsic Motivation Inventory scale $(\alpha=0.83$, [67]) used in both studies in Przybylski and Weinstein [12], including the two items measuring trust $(r=0.53$, $p<0.001)$. We did not include other measures from the original article, but we had three other items on relationship quality $(\alpha=0.78)$ and two items on the appreciation of and interest in the conversation $(r=0.68, p<0.001)$.

Results. In Study 2, we followed the same analytical methods as in Study 1. 
Relationship quality (Przybylski and Weinstein [12]). Tables 4 and 5 present the detailed results of the multilevel analyses controlling for gender, age and positive affect $(\alpha=0.84$, PANAS [69]). As in Study 1, there was no significant difference between both conditions on relationship quality (including trust), and additional relationship items, all $p s>0.29$. Also, no difference was observed on experience appreciation and interest, $t(68)=-0.74, p=0.47$. Gender was related to relationship quality and experience appreciation, such that women indicated a higher relationship quality and appreciation of the conversation, both $p s<0.03$. Positive affect was positively related to all relationship measures, all $p s<0.001$.

Group creativity. $N=12$ students from a European business school assessed the originality and appropriateness of the toys created by groups in exchange for 25 euros. They were invited in sessions of two to six participants in a large room where all the toy designs were displayed in one of three random orders. They were given the same toy task instructions as in Study 1 and proceeded to rate each design in terms of overall creativity (1-10 = "not at all / extremely creative"), originality (3 items, 1-10, "not at all" / "extremely original / novel / innovative") and appropriateness (2 items, 1-10, "not at all" / "extremely useful / appropriate"). Finally, they evaluated how much parents would be willing to pay for each toy and completed a final questionnaire including demographics. We first averaged the 12 valid judges' ratings on overall creativity ( $\alpha=0.86)$, originality ( $\alpha=0.88)$, novelty $(\alpha=0.86)$, and innovativeness $(\alpha=0.88)$. These four scores loaded on a single factor $(\alpha=0.98)$ and were thus averaged to obtain an overall originality index $(M=4.92, S D=1.46)$. Then, we averaged the 12 judges' ratings on usefulness $(\alpha=0.75)$ and appropriateness $(\alpha=0.62)$, and computed their average $(r=0.70$, $p<0.001)$ to create an overall appropriateness index $(M=5.86, S D=0.92)$. The 12 raters' estimated parents' willingness to pay had a high Cronbach alpha $(\alpha=0.87)$ and were averaged to create a willingness to pay index, that we logtransformed (Kolmogorov-Smirnov test, $D(70)=$ $0.24, p<0.001)$.

A series of $t$ tests did not reveal any significant differences between conditions on overall originality, $t(68)=0.16, p=0.88$, overall appropriateness, $t(68)=1.19, p=0.24$, or willingness to pay, $t(68)=0.79, p=0.43$ (S5 Table).

Self-assessments of toy creativity. Multilevel analyses did not reveal any effect of the mere presence of a smartphone on self-assessed toy originality, self-assessed toy appropriateness, or satisfaction, all $p s>0.88$ (S6 Table).

Table 4. Descriptive statistics of relationship measures (Study 2). Means and standard deviations by condition, sample sizes. Comparison with information reported in Przybylski and Weinstein [12].

\begin{tabular}{|c|c|c|c|}
\hline & & Phone & Notebook \\
\hline & $N_{\text {groups }}$ & $M(S D)$ & $M(S D)$ \\
\hline \multicolumn{4}{|l|}{ Przybylski and Weinstein [12]. Study 1} \\
\hline Relationship quality & 37 & \multicolumn{2}{|c|}{$2.78(0.79)$} \\
\hline Partner closeness & 37 & \multicolumn{2}{|c|}{$3.57(1.46)$} \\
\hline \multicolumn{4}{|l|}{ Przybylski and Weinstein [12]. Study 2} \\
\hline Relationship quality & 34 & \multicolumn{2}{|c|}{$4.98(1.09)$} \\
\hline Trust & 34 & \multicolumn{2}{|c|}{$3.25(1.01)$} \\
\hline Partner empathy & 34 & \multicolumn{2}{|c|}{$4.98(1.09)$} \\
\hline \multicolumn{4}{|l|}{ Study 2 (this paper)-Triads } \\
\hline Relationship quality & 70 & $4.96(1.06)$ & $4.91(1.11)$ \\
\hline Trust (subscale) & 70 & $5.65(1.28)$ & $5.62(1.23)$ \\
\hline Additional items relationship quality & 70 & $5.32(1.13)$ & $5.17(1.39)$ \\
\hline Experience appreciation & 70 & $5.67(1.24)$ & $5.84(1.21)$ \\
\hline
\end{tabular}

https://doi.org/10.1371/journal.pone.0251451.t004 
Table 5. Multilevel analyses for relationship measures (Study 2). Intraclass correlations, fixed effects estimates, and significance tests for the manipulation and covariates. Comparison with results reported in Przybylski and Weinstein [12].

\begin{tabular}{|c|c|c|c|c|c|c|c|c|c|c|c|c|c|}
\hline & \multirow[b]{3}{*}{ ICC } & \multirow{2}{*}{\multicolumn{3}{|c|}{$\begin{array}{c}\text { Fixed effect level-2 } \\
\text { phone }\end{array}$}} & \multirow{2}{*}{\multicolumn{3}{|c|}{$\begin{array}{c}\text { Fixed effect level-1 } \\
\text { covariate gender }\end{array}$}} & \multirow{2}{*}{\multicolumn{3}{|c|}{$\begin{array}{c}\text { Fixed effect level-1 } \\
\text { covariate age }^{\mathrm{a}}\end{array}$}} & \multirow{2}{*}{\multicolumn{3}{|c|}{$\begin{array}{c}\text { Fixed effect level-1 } \\
\text { covariate positive affect }^{\mathrm{a}}\end{array}$}} \\
\hline & & & & & & & & & & & & & \\
\hline & & $\boldsymbol{b}$ & $t$ & $p$ & $b$ & $t$ & $p$ & $b$ & $t$ & $p$ & $\boldsymbol{b}$ & $t$ & $p$ \\
\hline \multicolumn{14}{|c|}{ Przybylski and Weinstein [12]. Study 1} \\
\hline Relationship quality & $0.43-0.51$ & -0.99 & 3.08 & 0.004 & -20 & -0.61 & 0.55 & -0.04 & -0.03 & 0.12 & 0.80 & 2.99 & $<0.001$ \\
\hline \multirow[t]{2}{*}{ Partner closeness } & \multirow[t]{2}{*}{$0.43-0.51$} & \multirow[t]{2}{*}{-0.39} & \multirow[t]{2}{*}{-2.56} & \multirow[t]{2}{*}{0.02} & $-0.00-$ & \multirow[t]{2}{*}{$-0.06--0.64$} & \multirow[t]{2}{*}{$>0.51$} & $-0.00-$ & \multirow[t]{2}{*}{$-0.06--0.64$} & \multirow[t]{2}{*}{$>0.51$} & $-0.00-$ & \multirow[t]{2}{*}{$-0.06--0.64$} & \multirow[t]{2}{*}{$>0.51$} \\
\hline & & & & & -0.09 & & & -0.09 & & & -0.09 & & \\
\hline \multicolumn{14}{|c|}{ Przybylski and Weinstein [12]. Study 2} \\
\hline Relationship quality & $0.39-0.47$ & -0.19 & -2.29 & 0.03 & $0.01-0.09$ & $0.13-1.28$ & $>0.20$ & $0.01-0.09$ & $0.13-1.28$ & $>0.20$ & $0.01-0.09$ & $0.13-1.28$ & $>0.20$ \\
\hline Trust & $0.39-0.47$ & -0.36 & -3.76 & $<0.001$ & $0.02-0.13$ & $-0.13-1.50$ & $>0.12$ & $0.02-0.13$ & $-0.13-1.50$ & $>0.12$ & $0.02-0.13$ & $-0.13-1.50$ & $>0.12$ \\
\hline Partner empathy & $0.39-0.47$ & -0.37 & -3.60 & 0.002 & -0.08 & -0.29 & 0.77 & 0.04 & 1.92 & 0.06 & 0.21 & 1.55 & 0.13 \\
\hline \multicolumn{14}{|c|}{ Study 2 (this paper)-Triads } \\
\hline Relationship quality & 0.10 & 0.10 & 0.69 & 0.494 & 0.40 & 2.70 & 0.008 & 0.00 & 0.03 & 0.980 & 0.74 & 6.77 & $<0.001$ \\
\hline Trust (subscale) & 0.10 & 0.05 & 0.27 & 0.788 & 0.20 & 1.09 & 0.278 & 0.00 & 0.15 & 0.880 & 0.52 & 3.78 & $<0.001$ \\
\hline Additional items & \multirow[t]{2}{*}{0.12} & \multirow[t]{2}{*}{0.20} & \multirow[t]{2}{*}{1.06} & \multirow[t]{2}{*}{0.295} & \multirow[t]{2}{*}{0.33} & \multirow[t]{2}{*}{1.94} & \multirow[t]{2}{*}{0.054} & \multirow[t]{2}{*}{-0.00} & \multirow[t]{2}{*}{-0.15} & \multirow[t]{2}{*}{0.881} & \multirow[t]{2}{*}{0.98} & \multirow[t]{2}{*}{8.06} & \multirow[t]{2}{*}{$<0.001$} \\
\hline relationship quality & & & & & & & & & & & & & \\
\hline Experience appreciation & 0.14 & -0.12 & -0.74 & 0.465 & 0.38 & 2.24 & 0.026 & -0.00 & -0.05 & 0.961 & 0.72 & 5.71 & $<0.001$ \\
\hline
\end{tabular}

Confidence intervals are reported in the $\mathrm{S} 4$ Table.

${ }^{a}$ Age and positive affect are grand-mean centered.

Creativity process measures. We ran multilevel analyses on all process measures (S6 Table) and no difference emerged between conditions on easiness or enjoyment of the creative process, group cohesion, risk-taking or motivation, competence or autonomy, all $p s>0.20$. There was no effect on mind wandering, feelings of busyness, and approach/avoidance measures either, all $p s>0.13$.

Discussion. In contrast to Przybylski and Weinstein's [12] results and as in Study 1, Study 2 failed to reveal any effect of the mere presence of a smartphone [vs. a notebook) on relationship quality following a conversation between strangers. In addition, we failed to replicate the results observed in Study 1 on triads' creativity.

\section{General discussion}

In two studies, we failed to replicate Przybylski and Weinstein's [12] results showing an adverse effect of the mere presence of a mobile phone on relationship formation, when considering both dyads and triads of strangers. We also did not find any effect of the mere presence of a mobile phone on any aspect of creative cognition, examining both divergent and convergent creativity processes and outputs, and both group and individual creativity. These results suggest that mere presence of a mobile phone may not be as harmful as has been previously claimed $[12,13]$.

\section{Non-replication of Przybylski and Weinstein (2013)}

The failed replication result directly adds to the line of research on the negative consequences of the mere presence of a mobile device $[12,13,49-51]$, by suggesting that this negative influence may not be as marked as was previously assumed. If we cannot exclude that there might be other instances where this presence is harmful, our findings at least point out the fragility of 
the phenomenon. At a broader level, our results also nuance the dominant view that smartphones and technology are harmful, adding to burgeoning research that is casting doubt on the pervasiveness of their negative effects [e.g., 4, 8, 77]. Our findings also complement research on mere exposure effects [78-80]. Finally, our research supports the importance of replications [e.g., 29, 81, 82]: Until an effect has been independently replicated, researchers need to remain cautious in assuming its existence $[28,31]$.

Despite our best efforts to conduct the closest replication as possible, our studies contain limitations. First, null effects do not invalidate an effect. It may be that the mere presence of the phone is harmful in different populations from those we sampled (e.g., in populations where the use of the smartphone may not be as pervasive as in large European cities). Second, even though our sample sizes were much greater than those in Przybylski and Weinstein [12], they may not have provided enough power to detect an effect [77]. Third, we measured relationship quality after the creative tasks and self-reports on the creative process, which might have wiped out the effect due to fatigue or contamination.

Is there a way to reconcile our results with those of Przybylski and Weinstein [12]? We see several possibilities, all of which relate to the timing of our experiments. We collected our data in 2018, compared to Przybylski and Weinstein (in or before 2012) [12]. The first possibility is that people might have simply gotten used to the presence of mobile devices, which could make them immune to their mere presence. Relatedly, our sample included mainly participants in their twenties, that belong to a generation who grew up with smartphones, and thus who might find their presence very natural. Another reason could be that the technology has evolved greatly between 2012 and 2018. Przybylski and Weinstein [12] used a cellphone, while we used a smartphone. Indeed, the number of smartphone users worldwide has more than doubled during this interval [83]. Additionally, people have developed strong bonds to them, although this is less likely to explain our results since in our studies, participants were exposed to a lab device $[77,84,85]$. If any of these conjectures were true, then our findings would provide an updated assessment of the social consequences of the mere presence of a mobile phone, suggesting that its effect was short-lived.

\section{Null effect on creativity}

The absence of evidence supporting a link between the mere presence of a smartphone and creativity advances the exploration of the effects of technology on idea generation. Our results suggest that the mere presence of a technological device like a smartphone may not affect general measures of creativity, whether positively or negatively. Previous research has pointed out the critical role of the environment for creativity which can be affected by incidental cues like sound or background color or the presence of physical objects [66, 86-90]. Relatedly, a lay belief exists that a creative environment should be free from any distractions [91, 92]. Our findings suggest that creativity may not be that sensitive to the mere presence of technology.

One limitation of this investigation is that participants did the creativity tasks only after the conversation. However, in the real-world, creativity endeavors are rarely isolated from other processes, and we would argue that this improbably caused our null effects.

\section{Implications and avenues for future research}

The main implication of this research is to moderate calls to completely isolate from smartphones' presence. It may not be necessary to ban even switched off smartphones from the dinner table or to enforce strict cellphone policies in organizations [93-96]. For instance, the American, French and British governments have a no-phone policy during meetings, whereby each member has to leave their phones at the entry of the meeting room [97]. Our findings 
suggest that these constraints could be partly released, at least for meetings in which there is no concern that sensible information may be recorded.

Of course, when people's own smartphones are present, the temptation to use them might still be detrimental for social interactions or creativity [19, 98, 99]. In Misra et al. [13] for instance, acquaintances in the mere presence of their own mobile devices experienced a lower relationship quality, although similarly to Przybylski and Weinstein [12], this finding remains to be replicated. In a study we do not report here, we investigated whether individual idea generation could be affected by the presence of one's own smartphone. Again, we observed no effect on creative cognition. At this point, it is our view that there is not much influence of the mere presence of a phone on creative cognition. What may be worthwhile investigating are ways in which smartphones may impact creativity, other than via their mere presence. For instance, future research could explore the difference between generating ideas on one's smartphone rather than on one's personal computer [84, 85]. This could also be interesting when exchanging ideas with other people, in the wake of research on electronic brainstorming [100102]. More broadly, the topic of creativity and technology still offers a wide field of investigation.

\section{Conclusion}

We did not replicate Przybylski and Weinstein's [12] finding that the mere presence of a mobile device impairs relationship quality, nor did we find any effect of this presence on creativity. There is one practical recommendation arising from our results: next time you meet a stranger or work on a creative task, you may leave your phone on the table. Just turn on the airplane mode.

\section{Supporting information}

S1 Picture. Pictures of the smartphone and notebook in the study room (Studies 1 and 2). (DOCX)

S1 Appendix. Additional information regarding the manipulation and participants' reactions to the presence of the smartphone and the notebook (Studies 1 and 2). (DOCX)

S2 Appendix. Instructions for the toy creativity task (Studies 1 and 2). Translation from local language.

(DOCX)

S3 Appendix. Remote associates test (Study 1). Translation from local language. (DOCX)

S4 Appendix. Final questionnaire (Study 1). Translation from local language. (DOCX)

S5 Appendix. Final questionnaire (Study 2). Translation from local language. (DOCX)

S1 Table. Multilevel analyses for relationship measures of all group sizes (Study 1). Means and standard deviations by condition, sample sizes. Intraclass correlations, fixed effects estimates, significance tests, and confidence intervals for the manipulation and covariates. Comparison with results reported in Przybylski and Weinstein [12].

(XLSX) 
S2 Table. $t$ tests for toy creativity scores of all group sizes (Study 1 ). Means and standard deviations by condition, $t$ test values, significance tests, and confidence intervals.

(XLSX)

S3 Table. Multilevel analyses for self-assessments of creativity and creative measures of all group sizes (Study 1). Means and standard deviations by condition, intraclass correlations, fixed effect estimates, significance tests, and confidence intervals. (XLSX)

S4 Table. Multilevel analyses for relationship measures with confidence intervals (Study 2). Means and standard deviations by condition, sample sizes. Intraclass correlations, fixed effects estimates, significance tests, and confidence intervals for the manipulation and covariates. Comparison with results reported in Przybylski and Weinstein [12]. (XLSX)

S5 Table. $t$ tests for toy creativity scores (Study 2 ). Means and standard deviations by condition, $t$ test values, significance tests, and confidence intervals. (XLSX)

S6 Table. Multilevel analyses for self-assessments of creativity and creative measures (Study 2). Means and standard deviations by condition, intraclass correlations, fixed effect estimates, significance tests, and confidence intervals.

(XLSX)

S1 Code. $R$ code for multilevel analyses and ICCs (Studies 1 and 2). (R)

S1 Dataset. Self-reported measures (Study 1). Relationship measures, self-assessment of creativity, and creative measures.

(XLSX)

S2 Dataset. Creativity scores for group toys (Study 1). Ratings by peer judges. (XLSX)

S3 Dataset. Self-reported measures (Study 2). Relationship measures, self-assessment of creativity, and creative measures.

(XLSX)

S4 Dataset. Creativity scores for group toys (Study 2). Ratings by peer judges. (XLSX)

S1 File. Variable information (Studies 1 and 2). Variable names, labels, and values for all datasets.

(XLSX)

\section{Author Contributions}

Conceptualization: Claire Linares, Anne-Laure Sellier.

Data curation: Claire Linares.

Formal analysis: Claire Linares.

Funding acquisition: Anne-Laure Sellier.

Investigation: Claire Linares. 
Methodology: Claire Linares, Anne-Laure Sellier.

Supervision: Anne-Laure Sellier.

Validation: Anne-Laure Sellier.

Writing - original draft: Claire Linares.

Writing - review \& editing: Anne-Laure Sellier.

\section{References}

1. Nielsen. The Nielsen Total Audience Report April 2020. 2020 Apr 4 [Cited 2021 Jan 8]. Available from: https://www.nielsen.com/us/en/insights/report/2020/the-nielsen-total-audience-report-april-2020/

2. Salmons H. For Digital Awareness UK, Research: Teenage use of mobile devices during the night. 2016 Oct 6 [Cited 2021 Jan 8]. Available from: https://www.hmc.org.uk/blog/research-teenage-usemobile-devices-night/

3. Dowdell EB, Clayton BQ. Interrupted sleep: College students sleeping with technology. J Am Coll Health. 2019 Oct; 67(7): 640-646. https://doi.org/10.1080/07448481.2018.1499655 PMID: 30365360

4. Bjerre-Nielsen A, Andersen A, Minor K, Lassen DD. The negative effect of smartphone use on academic performance may be overestimated: Evidence from a 2-year panel study. Psychol Sci. 2020 Nov; 31(11): 1351-1362. https://doi.org/10.1177/0956797620956613 PMID: 33021885

5. Chu HS, Tak YR, Lee H. Exploring psychosocial factors that influence smartphone dependency among Korean adolescents. PloS ONE. 2020 May 13; 15(5): e0232968. https://doi.org/10.1371/ journal.pone.0232968 PMID: 32401789

6. Kushlev K, Dwyer R, Dunn EW. The social price of constant connectivity: Smartphones impose subtle costs on well-being. Curr Dir Psychol Sci. 2019 Aug; 28(4): 347-352.

7. Lanaj K, Johnson RE, Barnes CM. Beginning the workday yet already depleted? Consequences of late-night smartphone use and sleep. Organ Behav Hum Decis Process. 2014 May 1; 124(1): 11-23.

8. Orben A, Przybylski AK. The association between adolescent well-being and digital technology use. Nat Hum Behav. 2019 Feb; 3(2): 173-182. https://doi.org/10.1038/s41562-018-0506-1 PMID: 30944443

9. Rozgonjuk D, Levine JC, Hall BJ, Elhai JD. The association between problematic smartphone use, depression and anxiety symptom severity, and objectively measured smartphone use over one week. Comput Human Behav. 2018 Oct 1; 87: 10-17.

10. Oswald TK, Rumbold AR, Kedzior SG, Moore VM. Psychological impacts of "screen time" and "green time" for children and adolescents: A systematic scoping review. PloS ONE. 2020 Sep 4; 15(9): e0237725. https://doi.org/10.1371/journal.pone.0237725 PMID: 32886665

11. Twenge JM, Joiner TE, Rogers ML, Martin GN. Increases in depressive symptoms, suicide-related outcomes, and suicide rates among US adolescents after 2010 and links to increased new media screen time. Clin Psychol Sci. 2018 Jan; 6(1): 3-17.

12. Przybylski AK, Weinstein N. Can you connect with me now? How the presence of mobile communication technology influences face-to-face conversation quality. J Soc Pers Relat. 2013 May; 30(3): 237246.

13. Misra S, Cheng L, Genevie J, Yuan M. The iPhone effect: The quality of in-person social interactions in the presence of mobile devices. Environ Behav. 2016 Feb; 48(2): 275-298.

14. Mindberry. Disturbing infographic: Where people use their smartphones. 2015 Oct Cited 2021 (Jan 8]. Available from: https://www.mindberry.com/en/post/disturbing-infographic-where-people-use-theirsmartphones

15. Statista. Ranking of the smartphone penetration by country 2020. 2020 Oct 12 .

16. Colbert A, Yee N, George G. The digital workforce and the workplace of the future. Acad Manage J. 2016 May 9; 59(3): 731-739.

17. Forgays DK, Hyman I, Schreiber J. Texting everywhere for everything: Gender and age differences in cell phone etiquette and use. Comput Human Behav. 2014 Feb 1; 31: 314-321.

18. Korsgaard MA, Brower HH, Lester SW. It isn't always mutual: A critical review of dyadic trust. J Manage. 2015 Jan; 41(1): 47-70.

19. Roberts JA, David ME. My life has become a major distraction from my cell phone: Partner phubbing and relationship satisfaction among romantic partners. Comput Human Behav. 2016 Jan 1; 54:134141. 
20. Alter AL. Irresistible: The rise of addictive technology and the business of keeping us hooked. Penguin; 2017 Mar 7.

21. Huffpost. Cell phones may hurt interpersonal relationships just by being in the room, study says. Huffpost. 2012 May 9 [Cited 2021 Jan 11]. Available from: https://www. huffpost.com/entry/cell-phonehurts-relationships-study-university-of-essex_n_1855930?guccounter=1\&guce_referrer= aHR0cHM6Ly93d3cuZ29vZ2xILmNvbS8\&guce_referrer_sig= AQAAACZixUk4xKhWhZl14RQ5ryD3amncl67sJGnF72KhW1PDOTd8ayu-XC7wappJz8P1qsdXbGwTw2Zm-F9yP_tLJM_Rn4iWgfPo_18WKgv1y6sLFFBvLg7AN9Kxor3NDioREmxCKXNhurWx7ypSm9e2eypEtlbB7jjUSNAkUkpDid

22. Nierenberg C. Can't make new friends? Keep your smartphone off the table. 2012 Oct 4 [Cited 2021 Jan 11]. Available from: https://www.today.com/health/cant-make-new-friends-keep-yoursmartphone-table-flna6273737

23. Weinschenk S. The uncanny power of cell phones to disrupt relationships. Psychology Today. 2016 Nov 14 [Cited 2021 Jan 11]. Available from: https://www.psychologytoday.com/us/blog/brain-wise/ 201611/the-uncanny-power-cell-phones-disrupt-relationships

24. Courtright JA, Caplan SE. A meta-analysis of mobile phone use and presence. Human Communication \& Technology. 2020 Jul 31; 1(2): 20-35.

25. Allred RJ, Crowley JP. The "mere presence" hypothesis: Investigating the nonverbal effects of cellphone presence on conversation satisfaction. Commun Stud. 2017 Jan 1; 68(1): 22-36.

26. Caplan SE, Courtright JA. The effects of mobile device use and presence on perceptions of a conversation partner. West J Commun. Forthcoming. https://doi.org/10.1080/10570314.2013.786120 PMID: 25642121

27. Crowley JP, Allred RJ, Follon J, Volkmer C. Replication of the mere presence hypothesis: The effects of cell phones on face-to-face conversations. Commun Stud. 2018 May 27; 69(3): 283-293.

28. Asendorpf JB, Conner M, De Fruyt F, De Houwer J, Denissen JJA, Fiedler K, et al. Recommendations for increasing replicability in psychology. Eur J Pers. 2013 Mar; 27(2): 108-119.

29. Simmons JP, Nelson LD, Simonsohn U. False-positive psychology: Undisclosed flexibility in data collection and analysis allows presenting anything as significant. Psychol Sci. 2011 Nov; 22(11): 13591366. https://doi.org/10.1177/0956797611417632 PMID: 22006061

30. Simons DJ. The value of direct replication. Perspect Psychol Sci. 2014 Jan; 9(1): 76-80. https://doi. org/10.1177/1745691613514755 PMID: 26173243

31. Kerr NL. HARKing: Hypothesizing after the results are known. Pers Soc Psychol Rev. 1998 Aug; 2(3): 196-217. https://doi.org/10.1207/s15327957pspr0203_4 PMID: 15647155

32. Nosek BA, Spies JR, Motyl M. Scientific utopia: II. Restructuring incentives and practices to promote truth over publishability. Perspect Psychol Sci. 2012 Nov; 7(6): 615-631.

33. Tversky A, Kahneman D. Belief in the law of small numbers. Psychol Bull. 1971 Aug; 76(2): 105-110.

34. Meyvis T, Van Osselaer SMJ. Increasing the power of your study by increasing the effect size. J Consum Res. 2018 Feb 1; 44(5): 1157-1173.

35. Sternberg RJ, Lubart TI. The concept of creativity: Prospects and paradigms. Handbook of creativity. 1999; 1: 3-15.

36. Burroughs JE, Mick DG. Exploring antecedents and consequences of consumer creativity in a problem-solving context. J Consum Res. 2004 Sep 1; 31(2): 402-411.

37. Mehta R, Zhu M. Creating when you have less: The impact of resource scarcity on product use creativity. J Consum Res. 2016 Feb 1; 42(5): 767-782.

38. Amabile TM, Barsade SG, Mueller JS, Staw BM. Affect and creativity at work. Adm Sci Q. 2005 Sep; 50(3): 367-403.

39. Dahl DW, Moreau CP. The influence and value of analogical thinking during new product ideation. J Mark Res. 2002 Feb; 39(1): 47-60.

40. Gable SL, Hopper EA, Schooler JW. When the muses strike: Creative ideas of physicists and writers routinely occur during mind wandering. Psychol Sci. 2019 Mar; 30(3): 396-404. https://doi.org/10. 1177/0956797618820626 PMID: 30653407

41. Mehta R, Dahl DW, Zhu RJ. Social-recognition versus financial incentives? Exploring the effects of creativity-contingent external rewards on creative performance. J Consum Res. 2017 Oct 1; 44(3): 536-553.

42. Edmondson AC. Psychological safety and learning behavior in work teams. Adm Sci Q. 1999 Jun; 44 (2): 350-383.

43. Paulus PB, Dzindolet M, Kohn NW. Collaborative creativity-Group creativity and team innovation. In: Handbook of organizational creativity. Academic Press. 2012 Jan 1: 327-357. 
44. Carmeli A, Spreitzer GM. Trust, connectivity, and thriving: Implications for innovative behaviors at work. J Creat Behav. 2009 Sep; 43(3): 169-191.

45. Diehl M, Stroebe W. Productivity loss in brainstorming groups: Toward the solution of a riddle. J Pers Soc Psychol. 1987 Sep; 53(3): 497-509.

46. Edmondson AC, Kramer RM, Cook KS. Psychological safety, trust, and learning in organizations: A group-level lens. In: Kramer RM, Cook KS, editors. Trust and distrust in organizations: Dilemmas and approaches. New York: Russel Sage Foundation; 2004. pp 239-272.

47. Canale N, Vieno A, Doro M, Mineo ER, Marino C, Billieux J. Emotion-related impulsivity moderates the cognitive interference effect of smartphone availability on working memory. Sci Rep. 2019 Dec 6; 9(1): 18519. https://doi.org/10.1038/s41598-019-54911-7 PMID: 31811205

48. Ito M, Kawahara JI. Effect of the presence of a mobile phone during a spatial visual search. Jpn Psychol Res. 2017 Apr; 59(2): 188-198.

49. Thornton B, Faires A, Robbins M, Rollins $\mathrm{E}$. The mere presence of a cell phone may be distracting. Soc Psychol. 2014. 45(6): 479-488.

50. Ward AF, Duke K, Gneezy A, Bos MW. Brain drain: The mere presence of one's own smartphone reduces available cognitive capacity. J Assoc Consum Res. 2017 Apr 1; 2(2): 140-154.

51. Tanil CT, Yong MH. Mobile phones: The effect of its presence on learning and memory. PloS ONE. 2020 Aug 13; 15(8): e0219233. https://doi.org/10.1371/journal.pone.0219233 PMID: 32790667

52. Brown VR, Paulus PB. Making group brainstorming more effective: Recommendations from an associative memory perspective. Curr Dir Psychol Sci. 2002 Dec; 11(6): 208-212.

53. Finke RA, Ward TB, Smith SM. Creative cognition: Theory, research and application. Cambridge, MA: MIT Press; 1992.

54. Paulus PB, Nijstad BA. Group creativity: Innovation through collaboration. Oxford University Press; 2003.

55. Raaijmakers JG, Shiffrin RM. Search of associative memory. Psychol Rev. 1981 Mar; 88(2): 93-134.

56. Diehl M, Stroebe W. Productivity loss in idea-generating groups: Tracking down the blocking effect. J Pers Soc Psychol. 1991 Sep; 61(3): 392-403.

57. Dugosh KL, Paulus PB, Roland EJ, Yang HC. Cognitive stimulation in brainstorming. J Pers Soc Psychol. 2000 Nov; 79(5): 722-735. https://doi.org/10.1037//0022-3514.79.5.722 PMID: 11079237

58. Baird B, Smallwood J, Mrazek MD, Kam JW, Franklin MS, Schooler JW. Inspired by distraction: Mind wandering facilitates creative incubation. Psychol Sci. 2012 Oct; 23(10): 1117-1122. https://doi.org/ 10.1177/0956797612446024 PMID: 22941876

59. Yamaoka A, Yukawa S. Mind wandering in creative problem-solving: Relationships with divergent thinking and mental health. PLoS ONE. 2020 Apr 23; 15(4): e0231946. https://doi.org/10.1371/journal. pone.0231946 PMID: 32325483

60. Yang $\mathrm{H}$, Chattopadhyay A, Zhang K, Dahl DW. Unconscious creativity: When can unconscious thought outperform conscious thought? J Consum Psychol. 2012 Oct 1; 22(4): 573-581.

61. Moreau CP, Dahl DW. Designing the solution: The impact of constraints on consumers' creativity. J Consum Res. 2005 Jun 1; 32(1): 13-22.

62. Amabile TM. The social psychology of creativity: A componential conceptualization. J Pers Soc Psychol. 1983 Aug; 45(2): 357-376.

63. Mednick S. The associative basis of the creative process. Psychol Rev. 1962 May; 69(3): 220-232. https://doi.org/10.1037/h0048850 PMID: 14472013

64. Fitzsimons GM, Chartrand TL, Fitzsimons GJ. Automatic effects of brand exposure on motivated behavior: How Apple makes you "think different". J Consum Res. 2008 Jun 1; 35(1): 21-35.

65. Aron A, Aron EN, Smollan D. Inclusion of Other in the Self Scale and the structure of interpersonal closeness. J Pers Soc Psychol. 1992 Oct; 63(4): 596-612.

66. Mehta R, Zhu RJ. Blue or red? Exploring the effect of color on cognitive task performances. Science. 2009 Feb 27; 323(5918): 1226-1229. https://doi.org/10.1126/science.1169144 PMID: 19197022

67. McAuley E, Duncan T, Tammen VV. Psychometric properties of the Intrinsic Motivation Inventory in a competitive sport setting: A confirmatory factor analysis. Res Q Exerc Sport. 1989 Mar 1; 60(1): 4858. https://doi.org/10.1080/02701367.1989.10607413 PMID: 2489825

68. Davis MH. A multidimensional approach to individual differences in empathy. JSAS Catalog of Selected Documents in Psychology. 1980; 10: 85.

69. Watson D, Clark LA, Tellegen A. Development and validation of brief measures of positive and negative affect: the PANAS scales. J Pers Soc Psychol. 1988 Jun; 54(6): 1063-1070. https://doi.org/10. 1037//0022-3514.54.6.1063 PMID: 3397865 
70. Diener E, Emmons RA. The independence of positive and negative affect. J Pers Soc Psychol. 1984 Nov; 47(5): 1105-1117. https://doi.org/10.1037//0022-3514.47.5.1105 PMID: 6520704

71. Twisk JWR. Applied multilevel analysis: a practical guide for medical researchers. Cambridge University Press; 2006 Mar 28.

72. Finch WH, Bolin JE, Kelley K. Multilevel modeling using R. CRC Press; 2019 Jul 16.

73. Gooding RZ, Wagner JA III. A meta-analytic review of the relationship between size and performance: The productivity and efficiency of organizations and their subunits. Adm Sci Q. 1985 Dec; 1: 462-481.

74. Hülsheger UR, Anderson N, Salgado JF. Team-level predictors of innovation at work: a comprehensive meta-analysis spanning three decades of research. J Appl Psychol. 2009 Sep; 94(5): 1128-1145. https://doi.org/10.1037/a0015978 PMID: 19702361

75. Paulus PB. Group influence on individual task performance. In: Basic group processes Springer, New York, NY; 1983. pp. 97-120.

76. Carver CS, White TL. Behavioral inhibition, behavioral activation, and affective responses to impending reward and punishment: the BIS/BAS scales. J Pers Soc Psychol. 1994 Aug; 67(2): 319-333.

77. Kushlev K, Leitao MR. The effects of smartphones on well-being: Theoretical integration and research agenda. Curr Opin Psychol. 2020 May 20; 36: 77-82. https://doi.org/10.1016/j.copsyc.2020.05.001 PMID: 32563707

78. Bornstein RF. Exposure and affect: Overview and meta-analysis of research, 1968-1987. Psychol Bull. 1989 Sep; 106(2): 265-289.

79. Bornstein RF, D'Agostino PR. Stimulus recognition and the mere exposure effect. J Pers Soc Psychol. 1992 Oct; 63(4): 545-552. https://doi.org/10.1037//0022-3514.63.4.545 PMID: 1447685

80. Zajonc RB. Social facilitation. Science. 1965 Jul 16; 149(3681): 269-274. https://doi.org/10.1126/ science.149.3681.269 PMID: 14300526

81. Ioannidis JPA. Why most published research findings are false. PLoS Med. 2005 Aug 30; 2(8): e124. https://doi.org/10.1371/journal.pmed.0020124 PMID: 16060722

82. Open Science Collaboration. Estimating the reproducibility of psychological science. Science. 2015 Aug 28; 349(6251). https://doi.org/10.1126/science.aac4716 PMID: 26315443

83. Statista. Number of smartphone users worldwide from 2012 to 2021. 2020 Dec 20.

84. Melumad S, Meyer R. Full disclosure: How smartphones enhance consumer self-disclosure. J Mark. 2020 May; 84(3): 28-45.

85. Melumad S, Pham MT. The smartphone as a pacifying technology. J Consum Res. 2020 Jan 20; 47 (2): 237-255.

86. Atchley RA, Strayer DL, Atchley P. Creativity in the wild: Improving creative reasoning through immersion in natural settings. PloS ONE. 2012 Dec 12; 7(12): e51474. https://doi.org/10.1371/journal.pone. 0051474 PMID: 23251547

87. Mehta R, Dahl DW. Creativity: Past, present, and future. Consumer Psychology Review. 2019 Jan; 2 (1): 30-49.

88. Mehta R, Zhu R, Cheema A. Is noise always bad? Exploring the effects of ambient noise on creative cognition. J Consum Res. 2012 Dec 1; 39(4): 784-799.

89. Vohs KD, Redden JP, Rahinel R. Physical order produces healthy choices, generosity, and conventionality, whereas disorder produces creativity. Psychol Sci. 2013 Sep; 24(9): 1860-1867. https://doi org/10.1177/0956797613480186 PMID: 23907542

90. Ritter SM, Ferguson S. Happy creativity: Listening to happy music facilitates divergent thinking. PloS ONE. 2017 Sep 6; 12(9): e0182210. https://doi.org/10.1371/journal.pone.0182210 PMID: 28877176

91. Dul J. The physical environment and creativity. In: Kaufman JC, Sternberg RJ, editors. Cambridge handbook of creativity. 2019: pp 481-509.

92. Stokols $D$, Clitheroe $C, Z$ muidzinas $M$. Qualities of work environments that promote perceived support for creativity. Creat Res J. 2002 Apr 1; 14(2): 137-147.

93. Goodman R. Phone ban, Zizzi launches 'No Phone Zone' for Valentine's Day diners. The Sun. 2018 Feb 9 [Cited 2021 Jan 11]. Available from: https://www.thesun.co.uk/money/5533061/zizzi-launchesno-phone-zone-for-valentines-day-diners/

94. Herrera T. Hide your phone when you're trying to work. Seriously. The New York Times. 2018 Dec 2 [Cited 2021 Jan 11]. Available from: https:/www.nytimes.com/2018/12/02/smarter-living/be-moreproductive-hide-your-phone.html

95. Stratton M. Why your phone should have no place at the dinner table. Strive Global. 2020 Feb 21 [Cited 2021 Jan 11]. Available from: https://thriveglobal.com/stories/why-no-phones-dinner-tableconnect-focus-present-distraction/ 
96. Turkle S. Reclaiming conversation: The power of talk in a digital age. Penguin; 2016 Sep 26.

97. Hedges K. How to get people off their phones in meetings without being a jerk. Forbes. 2014 Jun 5 [Cited 2021 Jan 11]. Available from: https://www.forbes.com/sites/work-in-progress/2014/06/05/howto-get-people-off-their-phones-in-meetings-without-being-a-jerk/?sh=2d64fd213ee5

98. Chotpitayasunondh V, Douglas KM. The effects of "phubbing" on social interaction. J Appl Soc Psychol. 2018 Jun; 48(6): 304-316.

99. Dwyer RJ, Kushlev K, Dunn EW. Smartphone use undermines enjoyment of face-to-face social interactions. J Exp Soc Psychol. 2018 Sep 1; 78: 233-239.

100. Gallupe RB, Dennis AR, Cooper WH, Valacich JS, Bastianutti LM, Nunamaker JF Jr. Electronic brainstorming and group size. Acad Manage J. 1992 Jun 1; 35(2): 350-369.

101. Pinsonneault A, Barki H, Gallupe RB, Hoppen N. Electronic brainstorming: The illusion of productivity. Inf Syst Res. 1999 Jun; 10(2): 110-133.

102. Shepherd MM, Briggs RO, Reinig BA, Yen J, Nunamaker JF Jr. Invoking social comparison to improve electronic brainstorming: Beyond anonymity. J Manag Inf Syst. 1995 Dec 1; 12(3): 155-170. 